\title{
Mark Fisher
}

\section{Realismo capitalista: ¿No hay alternativa?}

Caja Negra, Buenos Aires, Argentina, 2016.

\section{Camilo Garber Fuentes*}

¿No hay alternativa al capitalismo? Y de ser así, ¿cuánto tiempo puede subsistir una cultura sin el aporte de lo nuevo? Estas son las dos grandes interrogantes que atraviesan Realismo capitalista: ¿No hay alternativa (en adelante Realismo capitalista) de Mark Fisher. Originalmente publicado en inglés en 2009, la traducción al español de este breve libro que mezcla filosofía, ciencias sociales y crítica cultural apareció

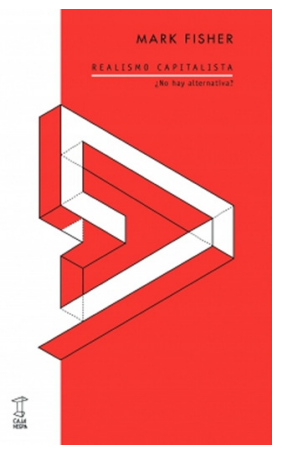
en 2016. Se trata de un trabajo ecléctico, dividido en nueve capítulos y un apéndice de dos artículos, que busca capturar y dar forma a la ontología del capitalismo tardío, afincado en la historia social reciente de Gran Bretaña, especialmente luego de la crisis económica de los créditos subprime de 2008.

A través de una entrada deductiva y trabajando la provocadora frase de Jameson (2003) "es más fácil imaginar el fin del mundo que el fin del capitalismo" (p. 76), Fisher (2016) nos explica lo que pretende transmitir con el concepto realismo capitalista, que alterna con neoliberalismo, el cual consiste en "la idea muy difundida de que el capitalismo no solo es el único sistema económico viable, sino que es imposible incluso imaginarle una alternativa" (p. 22). Cuando Margaret Thatcher durante la década de 1980 pronunciaba el adagio "no hay alternativa al capitalismo" (BBC, 2002), en rigor, sí existían opciones, aunque ellas, ya esmirriadas, no representaban un desafío sustantivo

\footnotetext{
Licenciado en Ciencia Política, Universidad Diego Portales, Santiago, Chile. E-mail: camilo.garber@mail.udp.cl
} 
al capitalismo tardío. El aserto adquiere mayor vigor, precisamente, cuando finaliza su mandato en 1990, suceso concomitante con la caída de los socialismos reales. Es ahí que el capitalismo como ideología se anota un logro fundamental y se consagra a la obtención de su triunfo final: un devenir inadvertido y la consolidación de la noción de que no existen alternativas fuera de él.

A esta dimensión ontológica del concepto de capitalismo tardío, Fisher añade la posición política y económica, propia de este tiempo, de entender los problemas públicos desde una perspectiva privada y ofrecer soluciones a ellas a partir de mecanismos de mercado. El autor también constata una serie de características empíricas que lo construyen, cuando apunta a

la globalización, el desplazamiento de las manufacturas por la computarización, la precarización del trabajo y la intensificación de la cultura de consumo. Estos rasgos constituyen el fundamento invisible de la realidad incontrovertible y ostensiblemente pospolítica sobre la que descansa el realismo capitalista.(Fisher, 2016, p. 129).

A ello podríamos sumar, de la mano de la obra, la creciente burocratización del Estado, que redunda en su inutilidad, pues no logra abordar a fondo los problemas más acuciosos al permanecer empantanada en la sofisticación metódica. En este punto, se genera un vínculo político entre el capitalismo tardío y el estalinismo, consistente en la radical importancia que se le asigna a la evaluación de los indicadores de desempeño por sobre la solución real de los problemas a los que buscan hacer frente. En este marasmo burocrático kafkiano, la responsabilidad final por los productos y servicios ofrecidos por el Estado termina por diluirse, volviéndose imposible identificar a un sujeto político sobre el cual la ciudadanía pueda ejercer control, más allá de los limitados espacios electorales.

Este ejercicio de comprensión del neoliberalismo es complementado por Fisher cuando se refiere a su relación con el Estado. No se trata solamente de la extendida noción que abjura de él en nombre de la expansión del mercado, sino de un doble discurso en constante tensión, el cual Fisher (2016) busca develar, "porque desde sus comienzos, el neoliberalismo dependió en secreto del Estado, incluso si fue ideológicamente capaz de denostarlo" (p. 23). En consecuencia, el capitalis- 
mo tardío pregona la disminución de la injerencia estatal, al mismo tiempo que depende profundamente de ella para su despliegue y su funcionamiento. Esta toma forma de prótesis, aplicando correcciones en caso de fallas, lo cual da lugar a una concepción del Estado como un espacio de poder a ser ocupado instrumentalmente, tal como "quedó espectacularmente en evidencia con la crisis financiera de 2008, cuando por invitación de ideólogos neoliberales el Estado se apuró a mantener el sistema bancario a flote" (Fisher, 2016, p. 23). En opinión del autor, este episodio hace evidente que las crisis económicas del capitalismo no nos acercan a su fin o, al menos, a las transformaciones que afecten su núcleo. Ellas revisten, a cambio, nuevas oportunidades para insistir en uno de sus mitos fundacionales: que no hay alternativa a él.

Como ideología, el neoliberalismo es exitoso pues ha sido naturalizado. Esta adopción generalizada se vincula con la comprensión extendida del neoliberalismo como un hecho, no como un valor alternativo en un sentido ético. Desde la revolución capitalista chilena, e incluyendo las administraciones de Thatcher en Gran Bretaña y Reagan en Estados Unidos, lo que se instaló fue la "ontología de negocios" constitutiva del realismo capitalista, según la cual es obvio "que todo en la sociedad debe administrarse como una empresa, el cuidado de la salud y la educación inclusive" (Fisher, 2016, p. 42), precisamente las áreas sociales que entran en crisis por el tipo de administración que las conducen actualmente, creando fisuras para la crítica ontológica.

Es frente a esta expansión y fijación del neoliberalismo que surgen las interrogantes con respecto a la cultura, las alternativas de organización social disponibles, el tenor de la temporalidad actual y, en términos más amplios, de la potencia política.

Lo que constata Fisher es, en palabras de Franco Berardi (2011), una "lenta cancelación del futuro" (p.13), en donde nos encontramos con una cultura incapaz de desafiarse a sí misma, un neoliberalismo hegemónico que no deja espacio a alternativas, un presente detenido y un futuro cancelado; en definitiva, una política agotada y estéril, sin capacidad transformativa.

Siguiendo a Jameson (1996), su trabajo sostiene que nos encontramos en un "tiempo desconectado" (citado en Fisher 2016), con una imaginación política incapaz de trascender la materialidad que lo define, lo que 
nos subsume en "una serie de presentes puros en el tiempo, desconectados entre sí” (Fisher, 2016, p. 54). Esta situación, propia del capitalismo tardío, provoca un colapso en la temporalidad, producto de la instantaneidad que nos aqueja, de la falta de perspectiva que nos causa pesar y de la carencia de proyecto alternativo para salir de la situación actual.

Esto es así en tanto lo nuevo surge en respuesta a lo ya establecido, mientras que lo actual se recompone en función de lo nuevo, pero, si no hay alternativas al esquema capitalista, "la tradición pierde sentido una vez que nada la desafía o modifica. Una cultura que solo se preserva no es cultura en absoluto" (Fisher, 2016, p. 24). En una relación donde es difícil establecer el origen de la causalidad, nos enfrentamos a un sistema que no admite alternativas y una política que no las puede crear, máxime respecto a la temprana simbiosis entre el neoliberalismo y neoconservadurismo (Brown, 2016), que en conjunto "minaron la esfera pública y la democracia, al producir un ciudadano que busca soluciones para sus problemas en las mercancías y no en los procesos políticos" (Fisher, 2016, p. 97), consagrando una política neutralizada, una democracia sin soberanía y un orden económico, también político, fuera de su alcance transformador.

Un ejemplo de ello sería la filantropía; frente a problemas acuciantes, ella exige la acción en nombre de una "inmediatez ética" (Fisher, 2016, p. 39). En consecuencia, la dificultad es doble. Por un lado, se ocupan dispositivos propios del problema para solucionarlo: en este caso, el dinero como sistema de equivalencia general, capaz de asignar valor monetario a todos los objetos culturales dentro del mercado, al mismo tiempo que una renuncia a la discusión política sustantiva con respecto a los fundamentos que dan origen a grupos sociales que, pese a estar insertos en el funcionamiento capitalista, requieren de acciones filantrópicas. El neoliberalismo ensalza al individuo y sus intereses, entendiéndolo como su propio promotor. Al mismo tiempo, postula que gracias al mercado el individuo se coordina y coadyuva con otros y sus proyectos. Al mismo tiempo, descree y teme de la agencia colectiva, la que se apura en catalogar como irracional y peligrosa, intentando desactivar lo público y promover lo privado.

Este panorama poco auspicioso para las alternativas al capitalismo responde, además de lo anotado, a la temprana lucidez política de los promotores del neoliberalismo. Ellos fueron "más leninistas que los le- 
ninistas: supieron crear y diseminar think-tanks que formaran la vanguardia intelectual capaz de crear el clima ideológico en el que el realismo capitalista pudiera florecer" (Fisher, 2016, p. 59). Es conocida la anécdota entre Anthony Fisher y Friedrich Hayek en la década de 1940, donde el primero buscó consejo del segundo para ingresar a la política, y este le recomendó financiar intelectuales para incidir en el clima de opinión. Casi ocho décadas más tarde el neoliberalismo dispone de la Red Atlas, que agrupa a prestigiosos centros de estudios, entre los que destacan el Institute of Economic Affairs, de Inglaterra, el Cato Institute de Estados Unidos y Libertad y Desarrollo en Chile.

También resulta poco auspiciosa la proyección de opciones al capitalismo por lo que Fisher identifica como el fenómeno de postergación indefinida. Apoyándose en Deleuze y Guattari (2009), observa que los procesos vitales se extienden indefinidamente, situación especialmente atingente en tiempos de pandemia, en donde estaríamos demasiado conectados como para concentrarnos. Así, por ejemplo,

la educación es un proceso de toda la vida; la capacitación para el trabajo abarca toda la vida laboral; el trabajo sigue en casa, se trabaja desde la casa o se está como en casa en el lugar de trabajo, etc. Una consecuencia de este ejercicio "indefinido" del poder es que la vigilancia externa ya no es tan necesaria: en gran medida la sustituye la vigilancia interna. (Fisher, 2016, p. 51).

Esta interiorización de la vigilancia y la autoexplotación que conlleva (Han, 2014), se entronca con los dispositivos de disciplinamiento de las sociedades modernas (Foucault, 2008), y también con la expansión de la deuda financiera, configurando la cerrazón de las sociedades de control. En conjunto, vienen a confirmar la sobrevaloración ideológica de la subjetividad interna propia de la ideología capitalista, pues "estamos autorizados a seguir participando en el intercambio capitalista siempre que consideremos que el capitalismo es algo muy malo solo en nuestro fuero interno" (Fisher, 2016, p. 37). Una vez más nos enfrentamos a la dislocación entre creencias y acciones, por variadas formas de modelación de la conducta social, que redundan en una esterilidad política para pensar alternativas.

Esta impotencia política, que se puede interpretar como una de tipo apolítica, por despojarla de su característica más propia, esto es, 
la capacidad transformadora, se refuerza en atención a lo que Fisher (2016) señala como "hedonia depresiva" (p.50). En base a la experiencia del autor como docente en varios niveles educativos en Inglaterra, y en oposición a la anhedonia, que consiste en la incapacidad patológica de sentir placer, la hedonia depresiva ilustra la incapacidad de las nuevas generaciones de realizar acciones diferentes a las que no le retribuyan placer. En este cuadro, cualquier esfuerzo no placentero es considerado como supererogatorio, dificultando in extremis cualquier opción de diagramar alternativas que renueven la cultura y que desafíen el panorama político y económico actual.

Son estas las características estructurales y los fundamentos del realismo capitalista. Ellos generan un ambiente que condiciona la producción cultural y dificulta la regulación política de la economía, erigiendo una rémora difícil de soslayar para un pensamiento alternativo y una acción política sustantiva, pues cuando el capitalismo adviene, produce un amplio movimiento cultural en donde la política pierde una cuota no despreciable de su capacidad de gobierno, a manos de un sistema sui géneris que desmantela el aparato legal y genera uno propio acorde a sus necesidades. Tal es el poder y alcance del capitalismo tardío, el que excede la esfera económica para proyectarse hacia las bases constitucionales y políticas de las sociedades en las que se despliega.

Otra forma de comprender al capitalismo tardío, según Fisher, radica en vislumbrar el tránsito desde el fordismo hacia el posfordismo. Este proceso, aún en marcha, comienza en 1979 cuando los gobiernos, mediante su política económica y monetaria, propician condiciones para una actividad económica que funciona mayormente en consideración de la oferta antes que la demanda. Este cambio viene aparejado de la flexibilización del capital y el trabajo, consistente en la desregulación del primero y la precarización del segundo.

La liberalización de capitales favorece su acumulación, una dinámica que se encuentra en el núcleo de la doctrina neoliberal concentrando el poder económico a tal punto que se encuentra en posición de hacer frente al poder político. La precarización del trabajo, por su parte, mina la potencia sindical que, si bien históricamente no se ha constituido como una alternativa neoliberal, sí fue capaz de limitar la extensión de su despliegue. 
Luego de su diagnóstico, la obra transita a esbozar una crítica a la izquierda debido a su incapacidad de generar organizaciones sociales alternativas. El pensamiento y la imaginación, arguye Fisher, funcionan como prolegómenos a la acción política. El desafío del pensamiento político consiste en superar las antiguas soluciones estatistas. Lo novedoso, al rescate del presente, consistiría en llenar de significado el concepto de voluntad general, poniendo al Estado al servicio de ella y actualizando la idea de espacio público, en donde la democracia se oponga a la reducción analítica que lo prefigura como un "mero agregado de individuos con intereses particulares"(Fisher, 2016, p. 116).

Asimismo, el desafío de la acción política estriba en politizar toda área de dominio capitalista que sea susceptible de ser modificada, una acción que "requiere de un agente político que transforme en un terreno de batalla lo que se da por descontado" puesto que "un anticapitalismo efectivo no debería ser una reacción al capitalismo, sino un rival suyo" (Fisher, 2016, pp. 119 y 118). Si bien Fisher no entrega recetas ni soluciones, sí ofrece pistas como líneas de acción, las que por su multiplicidad ejercen presión sobre la monopolización de la realidad, creando grietas hacia nuevos tiempos: reducción de la burocracia, afirmación de la autonomía del trabajador, disputa de la ontología de negocios; recuperación de los derechos sociales sustantivos y revitalización de la democracia.

En suma, el libro reseñado es uno que se propone dar cuenta, a través de la reflexión académica y la crítica cultural, del tenor de los tiempos actuales, ejercicio de crucial importancia para ensayar alternativas a lo que Fisher comprende como realismo capitalista.

\section{Referencias}

BBC. (2002, 22 de marzo). A lifetime of public speaking. BBC News. Recuperado de http://news.bbc.co.uk/2/hi/uk_news/politics/1888444.stm

Berardi, F. (2011). After the Future. Chico, California: AK Press.

Brown, W. (2016). El pueblo sin atributos. La secreta revolución del neoliberalismo. Barcelona: Malpaso.

Deleuze, G., \& Guattari, F. (2009). El Anti-Edipo. Capitalismo y esquizofrenia. Buenos Aires: Paidós. 
Fisher, M. (2016). Realismo capitalista: ¿No hay alternativa? Buenos Aires: Caja Negra.

Foucault, M. (2008). Vigilar y castigar. Nacimiento de la prisión. Buenos Aires: Siglo XXI.

Han, B-C. (2014). Psicopolítica. Neoliberalismo y nuevas técnicas de poder. Barcelona: Herder.

Jameson, F. (1996). Teoría de la posmodernidad. Madrid: Trotta.

Jameson, F. (2003). Future City. New Left Review, 21, 65-79. Recuperado de https://newleftreview.org/issues/ii21/articles/fredricjameson-future-city.pdf 